\title{
Optical tissue clearing associated with 3D imaging: application in preclinical and clinical studies
}

\author{
Cinzia Brenna ${ }^{1,2} \cdot$ Carolina Simioni $^{3,4} \cdot$ Gabriele Varano $^{1} \cdot$ Ilaria Conti ${ }^{1} \cdot$ Eva Costanzi $^{1} \cdot$ Mattia Melloni $^{1}$. \\ Luca Maria Neri ${ }^{1,4}$ (1)
}

Accepted: 28 January 2022 / Published online: 2 March 2022

(C) The Author(s) 2022, corrected publication 2022

\begin{abstract}
Understanding the inner morphology of intact tissues is one of the most competitive challenges in modern biology. Since the beginning of the twentieth century, optical tissue clearing (OTC) has provided solutions for volumetric imaging, allowing the microscopic visualization of thick sections of tissue, organoids, up to whole organs and organisms (for example, mouse or rat). Recently, tissue clearing has also been introduced in clinical settings to achieve a more accurate diagnosis with the support of 3D imaging. This review aims to give an overview of the most recent developments in OTC and 3D imaging and to illustrate their role in the field of medical diagnosis, with a specific focus on clinical applications.
\end{abstract}

\section{Graphical abstract}

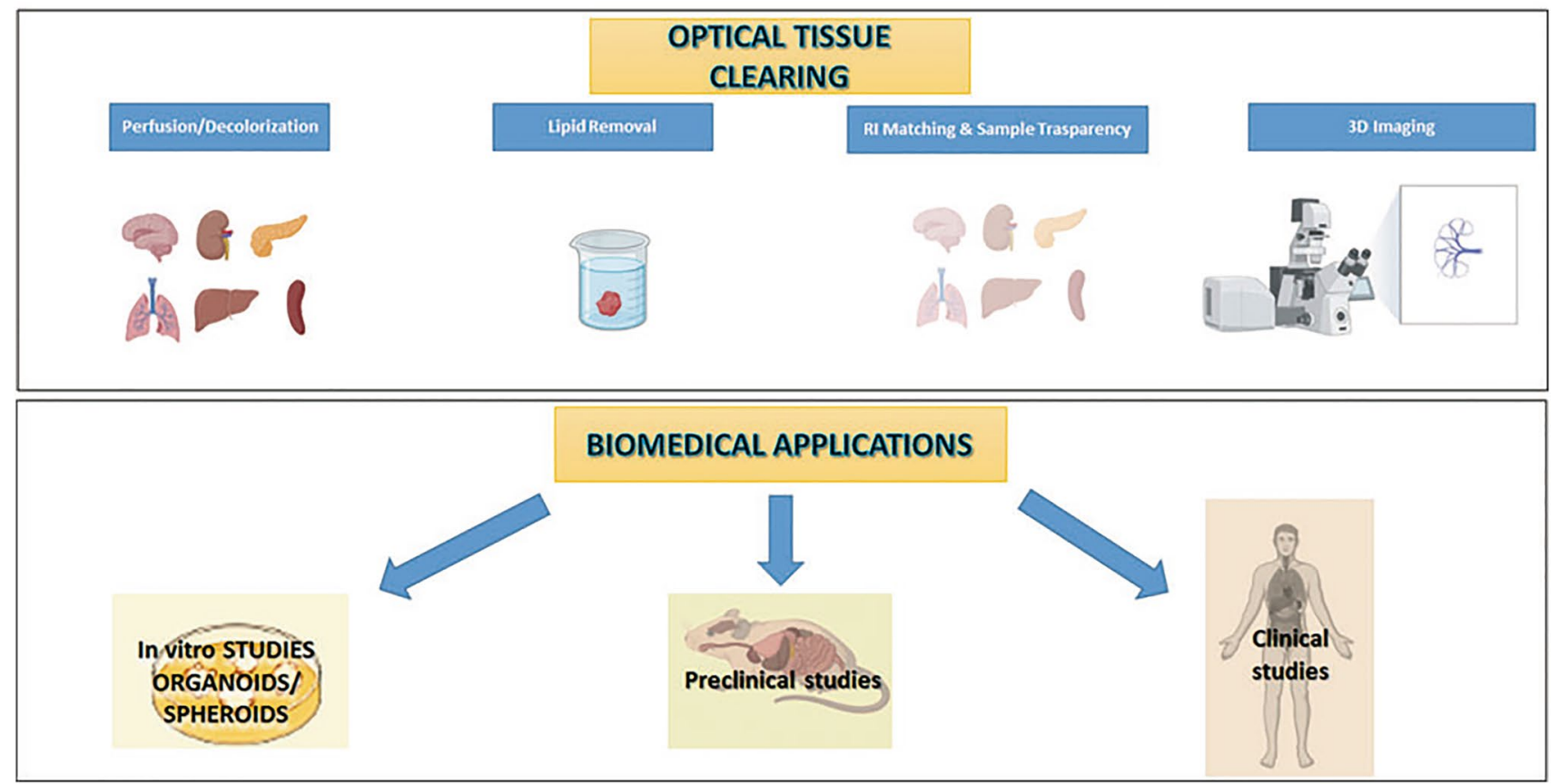

Keywords OTC $\cdot 3 \mathrm{D}$ imaging $\cdot$ Clinical diagnosis $\cdot$ Clinical applications $\cdot$ Oncology

Luca Maria Neri

luca.neri@unife.it
Abbreviations

2D

$3 \mathrm{D}$

BABB
Two-dimensional

Three-dimensional

Benzyl alcohol/benzyl benzoate

Extended author information available on the last page of the article 
CLARITY

CT

CUBIC

DISCO

Eci

ExM

FRUIT

FUnGI

GFP

GBM

MicroCT scan

MRI

OTC

OTC-3D imaging

PACT

PEGASOS

SBF-SEM

seeDB

STEM
Clear lipid-exchange acrylamide hybridized rigid imaging in situ hybridization-compatible tissue hydrogel

\section{Chemical shift imaging}

Computed tomography scanning

Clear, unobstructed brain/body

imaging cocktails and computational

analysis

Dimensional imaging of solvent-

cleared organs

Ethyl cinnamate

Expansion microscopy

Fructose and urea cocktail

Fructose, urea and glycerol for

imaging

Green fluorescent protein

Glioblastoma multiforme

X-ray microtomography

Magnetic resonance imaging

Optical tissue clearing

Optical tissue clearing combined with

3D imaging

Passive clearing tissue

Polyethylene glycol (PEG)-associated solvent system

Serial block face-scanning electron microscopy

See deep brain

Scanning transmission electron microscopy

\section{Introduction}

Optical tissue clearing (OTC) defines a wide set of protocols, aiming to make large and fixed biological samples optically transparent, where "large" refers to thick sections of tissue, organs, up to entire organisms (for example, mouse or rat) (Ariel 2017). The principle it is based on is the removal of the major sources of light scattering into the tissue, as, for instance, lipids and aqueous media interfaces, which generally create a mismatch of the refractive index and the consequent "milky appearance" that does not permit the light to propagate in straight lines (that is, the light scattering phenomenon) (Christopher 2006; Genina 2010; Richardson and Lichtman 2015).

In recent decades, the increasing need for a deeper understanding of morphological and developmental processes within organisms required more precise methodologies for three-dimensional (3D) imaging (Richardson and Lichtman 2015), using, for instance, confocal two-photon and light-sheet microscopy (Minsky, 1955 U.S. patent

$\mathrm{n}^{\circ}$ 3013467; Minsky 1988; Denk 1990; Keller and Dodt 2012). A schematic illustration of the operating principle of these microscopes is reported in Fig. 1.

The importance of 3D imaging lies in solving the drawbacks of two-dimensional (2D) microscopic analysis (i.e., the time-consuming and prone-to-error sample preparation, the tissue degradation-due to the massive use of reagents-and slicing, resulting in reduced thickness and a consequent limited spatial resolution) (van Royen 2016; Poola 2019). The 3D imaging can undoubtedly improve the visualization of the samples, resulting in a higher amount of structural information provided (which is very small, considering the thickness of the 2D slices), as well as the spatial resolution (highly limited in the 2D) (Richardson and Lichtman 2015; Seo 2016). Moreover, when using $2 \mathrm{D}$ thin slices, the sample 3D reconstruction becomes hard to perform (Gómez-Gaviro 2020). Although some image-processing software might create histological 3D reconstructions, such as Fiji (Schindelin 2012), MATLAB (Křížek 2016), or Imaris (Au-Haass-Koffler 2012), this image stacking process is laborious, time-consuming, prone to error, and not wholly reliable (Gómez-Gaviro 2020).

On the other hand, a nontransparent tissue is not suitable for acquiring 3D high-resolution images due to the light scattering phenomenon. Therefore, so far, the best compromise to obtain 3D high-resolution images is to render them optically transparent by using clearing reagents (GómezGaviro 2020).

To date, OTC has been extensively used for the investigation of the structural architecture of other organs, especially kidney, muscle, bone, dental tissue, and human placenta, where the morphology of placental blood barriers was also evaluated (Winkler 2010; Kay 2013; Pauli 2017; Klingberg 2017; Carrillo 2018; Jing 2019; Huang 2019; Williams 2019). As demonstrated by Cai and coworkers (2019), who imaged a whole murine organism, OTC represents an essential tool that can be applied to a wide range of specimens (that is, a variety of organs from rodents, primates to humans), in a fast, safe, economical, easy-to-use, and highly reproducible way, at a single-cell resolution (Silvestri 2016; Kubota 2017). Actually, there is no universal OTC protocol, but rather the choice of one method depends on the sample, the specimens, and the fluorescent marker used. Kolesová and coworkers (2016) gave a clear example of this, testing and comparing five different OTC protocols [tetrahydrofuran dehydration and dibenzylether protocol (THF-DBE), SCALE, CLARITY, and CUBIC], and three imaging methods intended to preserve Green fluorescent protein (GFP) fluorescence in the central nervous system and for evaluating their ability to make mouse hearts and whole embryos transparent, concluding that the optimal method depends on the detail level required (Kolesová 2016). 


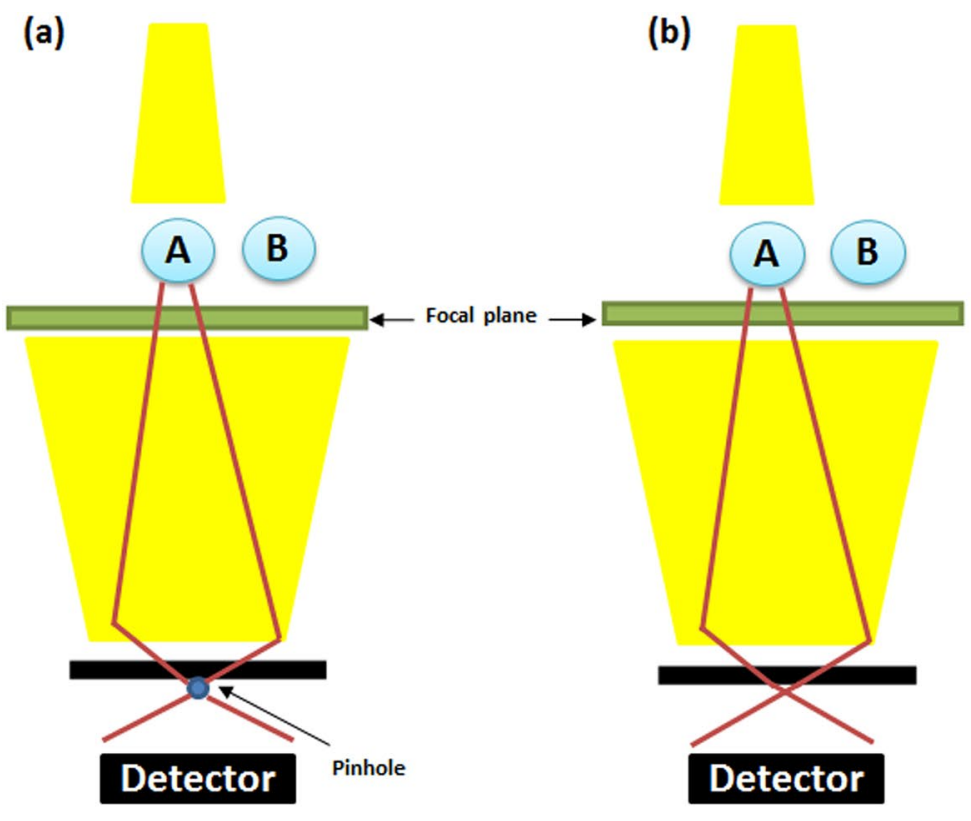

(c)

Fig. 1 Schematic workflow of the mode of action of confocal (a), two photon (b), and light sheet (c) microscopies. In diagrams (a) and (b), point A is represented in the focal plane, whereas point B is out-

Recently, it has been proposed to apply OTC approaches to discriminate between healthy and pathologic tissues to improve clinical and diagnostic settings, until now circumscribed only to 2D imaging. For instance, different human cleared biopsies were analyzed by 3D imaging (breast, prostate, kidney, brain, gingiva, skin, and temporal bones; Glaser 2017; Poola 2019). Moreover, OTC feasibility in clinical applications has been demonstrated by ascertaining histological differences between human benign and tumor prostate, as well as pancreatic lesions and adenocarcinomas (Hong 2019; Matryba 2019; van Royen 2016).

This innovative OTC-3D approach led to two great advantages: whole-mount tissue instead of thin slices and the acquisition of images at cellular resolution, which is essential, considering that the early stages of several pathologies depend on changes in the cellular morphology and functions (Antonacci and Braakman 2016).

The novelty of OTC-3D medical application imaging is the use of entire biopsies marked by specific fluorescent probes, making it a cost-effective, nonradioactive mode of imaging for cancer detection (Martinelli 2020).

Recent findings in OTC-3D imaging are focused on the improvement of near-infrared probes. This spectrum range $(700-850 \mathrm{~nm})$ permits absorption of light deeper than others emitting at $400-600 \mathrm{~nm}$, allowing a better tissue visualization and resulting in lower light absorption and minor autofluorescence by blood and other components in this side. Only the light sheet microscopy creates a light plane coincident with the focal plane, allowing the focus localization inside both of the points: https://biorender.com/

spectrum range (Martinelli 2020). Moreover, cancer tissues are often characterized by necrotic areas, which might not be imaged in standard conditions. Generally speaking, clearing agents combined with near-infrared probes enhance the light penetration in biological samples. In addition, lipid and natural pigment removal increase the refractive index matching and the spatial resolution, allowing a better sample analysis (Gómez-Gaviro 2020).

This review explores how OTC-3D imaging could be used in preclinical and clinical cancer research and other possible methods of life imaging and 3D visualization (not necessarily needing tissue clearing) as alternative approaches, currently used in the diagnostic field.

\section{D in vitro cancer research: the use of cleared organoids and spheroids}

Organoids are defined as human pluripotent or organ restricted (i.e., stomach, liver, or bladder) stem cell-derived 3D structures, which mimic cell heterogeneity, native histologic architectures, and cell-extracellular matrix interactions (i.e., breast, colon, pancreas, prostate, ovary-Eiraku 2008; Ham 2016; Ham 2017; Colella 2018; Khawar 2018; Lazzari 2018). Due to their self-assembling ability, organoids can grow into microscopic versions of parent organs suitable for 3D study (Perkhofer 2018; Dekkers 2019). As 
new 3D cellular models, organoids have been established and massively used in biology, oncology, and pharmacology (Lancaster 2013; Alépée 2014), representing an innovative tool for personalized and cancer medicine (Perkhofer 2018). Cancer is a multifactorial process based on genetic and environmental factors, and, currently, the study approaches are based above all on cultured tumor cell lines and animal models.

Compared with 2D and animal models, as well as with the whole-mount 3D imaging, the benefits in using organoids correlate in the following points: (a) 2D in vivo cellular models exhibit some downsides. Cells do not correctly interact between each other or with the surrounding extracellular matrix, especially in plastic surfaces, where the presence of oxygen and nutrients can be limited, further weakening the possibility to perform more accurate and precise cellular studies (Zschenker 2012; Duval 2017; Nürnberg 2020). Moreover, tumor cell lines may accumulate further mutations due to environmental interactions not representing the human complexity; (b) the genetic background of animal cancer models does not completely reflect human physiology (Perkhofer 2018). Therefore, human organoids may be considered a novel experimental model that overcomes the gap between animal models and human trials (Kim 2020); (c) the possibility to directly study human material, especially considering the accessibility of tumor material from patients (Perkhofer 2018); and (d) the limitations that are given by using only biopsies.

On the other hand, the use of organoids is often debated. The reasons could be the following: (a) organoids exhibit a superior morphology for glandular tissues but not appropriate for stratified tissue, as skin; (b) the organoid cultures were established to investigate normal cellular differentiation in the prostate (Lang 2001) and breast (Barcellos-Hoff 1989). In addition, it is not clear how tumor cells interact with basement membrane gel; (c) in vivo, tumor growth is anchorage-independent, but organoids are anchoragedependent, given their adherence to the basement membrane proteins in the gels; (d) in addition, in vivo, tumor cells grow as solid masses, whereas in the organoid system, they grow as hollow spheres, not recreating the actual patient morphology, so they do not always recreate patient tissue architecture (Lang 2019); (e) tumor tissues can also be contaminated by normal cells: a study of in vitro and in vivo models performed on tumor organoids showed a high percentage of normal cells (Pauli 2017). Therefore, when using organoids, it is fundamental to confirm the absence of all potential contaminants (Lang 2019); and (f) heterogeneity of organoids, which could be critical for discerning the ratio and type of cells (tumor, normal, different tumor clones).

Nevertheless, fluorescence microscopy, coupled with OTC and 3D imaging, has extensively contributed to characterizing organoid cellular composition and demonstrating their resemblance to the original tissue (Dekkers 2019). Furthermore, different OTC protocols on human cell-derived organoids have been established (Cora 2019; Dekkers 2019; Krieger 2020), allowing the study of the structural complexity, the map of the spatial distribution, phenotypic identity, and cellular state of all individual cells composing these 3D structures (Costa 2019; van Ineveld 2020). The principal advantages of these new approaches regard the suitability for different species and a wide variety of organs and the reduced processing time if compared with the classic OTC procedures, such as BABB, CLARITY, and others. A recent work published by Krieger et al. (2020) exemplarily demonstrated a similar approach in glioblastoma. This research showed that tumor cells within organoids mimic the in vivo glioblastoma multiforme (GBM) behavior in progression and invasiveness. Moreover, the transcriptional changes implicated in the invasion process have been reported and proved coherent with the GBM cell behavior, indicating that GBM cells could reactively upregulate genes required for their dispersion (Krieger 2020).

Compared to the conventional 2D methodology, the use of OTC-3D imaging to organoids allows deciphering complex cell morphology and tissue architecture. Furthermore, compared with the first OTCs, other approaches have already implemented a second generation of protocols, which is more undemanding and easy to enhance in laboratories. For example, the system designed by Rios and coworkers (2019) and shortened by van Ineveld and coworkers in a 3-day protocol, based on the use of a new clearing agent named FUnGI (fructose, urea, and glycerol for imaging), provided an organoid-clearing protocol for multi-color lineage tracing of tumor heterogeneity, which proved suitable both for intact organoids from different species, and organs (Rios 2019; van Ineveld 2020).

The 3D imaging of cleared organoids is compatible with different samples, rendering this approach the new frontier for studying different diseases and cancers and laying the foundations for a more precise personalized medicine.

\section{Preclinical and clinical applications of optical tissue clearing}

To date, conventional 2D histology is still the method of choice, although prone to limitations, in clinical and, in particular, in cancer research (Feuchtinger 2016). 2D histology is considered a reductionist approach, as the analysis of a single 2D tissue slice provides information about only a small percentage of the entire tumor area that will be detectable for studying, with a very high risk of false positives (Feuchtinger 2016; Almagro 2021). In the tumor analysis process, the definition of its growth rate from complex morphological structures is relevant, 
such as tumor vasculature, that can only be recognized and fully understood in its three dimensions. OTC-3D provides panoramic visualization of cancer-bearing organs and constitutes a powerful tool to analyze the tumor architecture, microenvironment, heterogeneity, and progression both in preclinical models and in patients (Almagro 2021). Various tissue-clearing methods (aqueous-, organic-, or hydrogel-based) were tested on tumor areas in preclinical models that revealed different degrees of optical transparency, tissue preservation, fluorescent signal conservation, and compatibility with 3D imaging and standard confocal microscopy (Lloyd-Lewis 2016). Table 1 provides an overview of the state of the art of OTC and their preclinical and clinical applications. Listing all the OTCs is beyond the scope of this table; instead, we want to focus on the more successful protocols used in preclinical and clinical models. The full name of the OTCs mentioned in the table is listed in the section "Abbreviations."

\section{Preclinical approaches of OTC}

Aqueous methodologies (i.e., fructose, glycerol, Scale, and SeeDB series) are easy to handle and have low toxicity. In addition, there is no significant volume change, and the fluorescence retainment is considerably higher than in organic protocols.

Generally speaking, most of the aqueous protocols do not include delipidation, causing a low rate of transparency/ translucency for whole mouse organs in healthy and diseased conditions (Lang 2001; Dobosz 2014; Cai 2018).

The second-generation aqueous OTCs were optimized to overcome this problem. This is the case with SeeDB, which, in the beginning, was conceived for studying the brain's connectome. Afterward, its use was extended to other organs, both in healthy and pathologic conditions. For enhancing the visualization of mammary ductal and lobulo-alveolar structures, SeeDB and CUBIC protocols were considered superior for volumetric fluorescence imaging and whole-mount histochemical staining, respectively (Lloyd-Lewis 2016).

Table 1 Overview of preclinical and clinical application of the most used optical clearing methods

\begin{tabular}{|c|c|c|c|c|}
\hline & Protocol name & Chemicals used & Preclinical application & Clinical application \\
\hline \multirow[t]{5}{*}{ Simple immersion } & Formamide & Formamide & Data not reported & Data not reported \\
\hline & FRUIT & Fructose/thioglycerol/urea & Data not reported & Data not reported \\
\hline & PEGASOS & $\begin{array}{l}\text { Polyethylene glycol (PEG)-associ- } \\
\text { ated solvent system }\end{array}$ & Data not reported & Data not reported \\
\hline & SeeDB series & Fructose/thioglycerol & Davis (2016) & Data not reported \\
\hline & Sucrose & Sucrose & Data not reported & Data not reported \\
\hline \multirow[t]{5}{*}{ Solvent-based } & BABB (series) & Benzoic acid/benzyl benzoate & $\begin{array}{l}\text { Lang et al. (2001); Dobosz, et al. } \\
\text { (2014) }\end{array}$ & Data not reported \\
\hline & DISCO (series) & Dichlormethane/DBE & $\begin{array}{l}\text { Ertürk et al. (2012); Tainaka et al. } \\
\text { (2014); Hong et al. (2020) }\end{array}$ & Tainaka (2014); Hong (2020) \\
\hline & ECi (series) & Ethyl-3-phenylprop-2-enoate & $\begin{array}{l}\text { van Royen et al. (2016); Brenna } \\
\text { et al. (2020) }\end{array}$ & (Avilov 2021) \\
\hline & FUnGI & Fructose, urea, glycerol & $\begin{array}{l}\text { Roi et al. (2019); van Ineveld et al. } \\
\text { (2020); Dawson et al. (2021) }\end{array}$ & Data not reported \\
\hline & THF-DBE & $\begin{array}{l}\text { Tetrahydrofuran dehydration and } \\
\text { dibenzylether }\end{array}$ & $\begin{array}{l}\text { Ertürk et al. (2012); Wang et al. } \\
\text { (2018); Dawson et al. (2021) }\end{array}$ & Data not reported \\
\hline \multirow[t]{2}{*}{ Hyperhydratation } & CUBIC & $4 \mathrm{M}$ Urea/50\% sucrose & $\begin{array}{l}\text { Davis et al. (2016); Guldner et al. } \\
\text { (2016); Kolesová et al. (2016) } \\
\text { Lloyd-Lewis et al. (2016); } \\
\text { Kubota et al. (2017); Tainaka } \\
\text { et al. (2018) }\end{array}$ & Nojima (2017) \\
\hline & Scale (series) & 4 M Urea/sorbitol & Kolesová et al. 2016 & Data not reported \\
\hline \multirow[t]{5}{*}{ Hydrogel embedding } & ACT-PRESTO & $\begin{array}{l}\text { Hydrogel/sodium dodecyl sulfate } \\
\text { (SDS) }\end{array}$ & Data not reported & Data not reported \\
\hline & CLARITY & FocusClear/80\% glycerol & $\begin{array}{l}\text { Kolesová et al. (2016), Lagerweij } \\
\text { et al. (2017) }\end{array}$ & $\begin{array}{l}\text { Glaser (2017), Hsueh (2017), } \\
\text { Chen (2019) }\end{array}$ \\
\hline & ExM & Hydrogel & $\begin{array}{l}\text { Brenna et al. (2020), Sun et al. } \\
(2020)\end{array}$ & Sun (2020) \\
\hline & MyoClear & Hydrogel monomer solution & Williams et al. (2019) & Data not reported \\
\hline & PACT & Hydrogel/SDS & Guldner et al. (2016) & Data not reported \\
\hline
\end{tabular}




\section{Solvent-based OTCs in preclinical models}

CUBIC is often considered the method of choice. The main advantage is that CUBIC chemicals elute endogenous chromophores (e.g., hemoglobin), reducing blood autofluorescence (Susaki 2014; Tainaka 2014; Kolesová 2016, 2021). In addition, CUBIC preserves fluorescence, allowing the protocol's performance after the immunolabeling, especially regarding whole-mount GFP cardiac mouse samples (Susaki 2014; Tainaka 2014; Kolesová 2016, 2021).

CUBIC protocol was optimized to optically clear mouse bones and detect cancer metastasis (e.g., lung, kidney) in different mouse models, for instance, by imaging the triplepositive breast cancer metastasis in bones and brain (Kubota 2017; Tainaka 2018; Takahashi 2020). CUBIC was also applied in preclinical models to detect the vessel architecture before and after kidney injury (Hasegawa 2019). However, the main downside lies in the long clearing period for larger specimens (Kolesová 2021).

CUBIC and PACT have been intensely used to clear whole organisms by replacing the electrophoretic force with perfusion pressure, but CUBIC seems to be used more widely (Wang 2018). For example, a modified CUBIC protocol was recently presented for the mouse heart tissue clearing and imaging, which enabled the visualization of the 3D network of cardiac innervation (Nehrhoff 2016; Yokoyama 2020). However, due to EDTP, a sticky solution and copperchelator, CUBIC does not allow a reliable evaluation of the protein loss after clearing (Susaki 2014). Indeed, it seems that CUBIC might cause a protein loss, ranging between 25 and 40\% (Richardson and Lichtman 2015). On the other hand, the presence of sodium dodecyl sulfate (SDS) in the clearing solution of PACT causes heavy tissue swelling (Yang 2014).

Solvent-based clearing agents are more compatible with whole-mount immunostaining and synthetic dyes. In addition, a dehydration step is often required for organ delipidation, allowing a higher sample transparency/translucency (Dobosz 2014; Tainaka 2017; Cai 2019; Hong 2020; Huang 2019; Brenna 2020). Dobosz and coworkers used the BABB technique for visualizing breast tumors, discerning the tumor morphology, vessel architecture, and drug distribution in breast cancer from xenograft mouse models (Dobosz 2014). Moreover, using a specific fluorescently labeled antibody, they also analyzed the drug distribution within the tumor area (Dobosz 2014; Ochoa 2018). Precancerous prostate lesions have been studied by OTC-3D imaging, using $500-\mu \mathrm{m}$-thick tissues from radical prostatectomy specimens (Verhoef 2019). Before clearing them with BABB, the models were stained with antibodies targeting keratin 8-18 and keratin 5 to detect luminal and basal cells, respectively. Interconnecting and blind-ending saccular tubules characterize the architecture of the peripheral and transition zone of the prostate gland, and the 3D imaging was capable of revealing a new variant of prostate atrophy (Verhoef 2019).

FUnGI protocol combined with multiphoton intravital was used to image mouse mammary ducts and alveoli with a single-cell resolution (Dawson 2021). In addition, they demonstrated the compatibility of this approach with the observation of complex single-cell behavior within mammary ducts within their 3D microenvironments (Dawson 2016; Dawson 2021). Moreover, it has been shown that FUnGI is also applicable to the study of early mammary tumorigenesis and development in pregnancy for both in vivo and ex vivo models (Jamieson 2017; Linde 2018; Rios 2019). However, as described by the authors, this procedure is limited to one imaging session only, not allowing longitudinal tracking of cells over days or weeks, making longer-term processes such as mammary ductal branching challenging to analyze (Dawson et al. 2021).

For some cases, solvent-based protocols seem to overcome the most common issues faced with other approaches, such as causing changes in the tissue structure and the easy performance (Ochoa et al. 2018). For instance, lungs appear challenging to render optically transparent and 3D image due to their spongy-like consistency. Different approaches have been carried out in healthy and tumor tissues. For example, Scott and coworkers (2014) presented a BABB clearing of murine lungs and human airways for the first time, describing a complex 3D relationship between nerves, vessels, and airway architecture and detecting new patterns and connectivity of pleural innervations (Scott et al. 2014). Novel 3D studies, combining immune-staining, solvent-based OTCs (BABB or DISCO), and 3D imaging, were also performed to explore lung cancer and fibrosis, which often occurs before cancer (Cuccarese et al. 2017; Ochoa et al. 2018; von Neubeck et al. 2018). BABB was also used to image the myocardial architecture (Kolesová et al. 2021).

However, solvent-based OTC limiting factors regard: (a) structural shrinkage due to dehydration. Moreover, with the delipidation process also being essential, structures with lipids might appear damaged and disappear; (b) the low clearing efficacy (in particular for BABB) and fluorescence preservation (Kolesová et al. 2021); (c) some pigments that increase the autofluorescence (such as hemoglobin and melatonin) are not entirely removed by the chemicals. Therefore, when studying mouse models, perfusion with PBS and PFA can optimize these limitations by reducing the autofluorescence and the heme content (Huang et al. 2019; Brenna et al. 2020); (d) some chemicals are harmful to the operator; e) the high environmental impact due to the chemicals used; and (f) the long process protocols, which can last from days to weeks. A solution could be found in optimizing the temperature for making more accessible the optical reagent into the tissues (Huang et al. 2019; Brenna et al. 2020). This is the case 


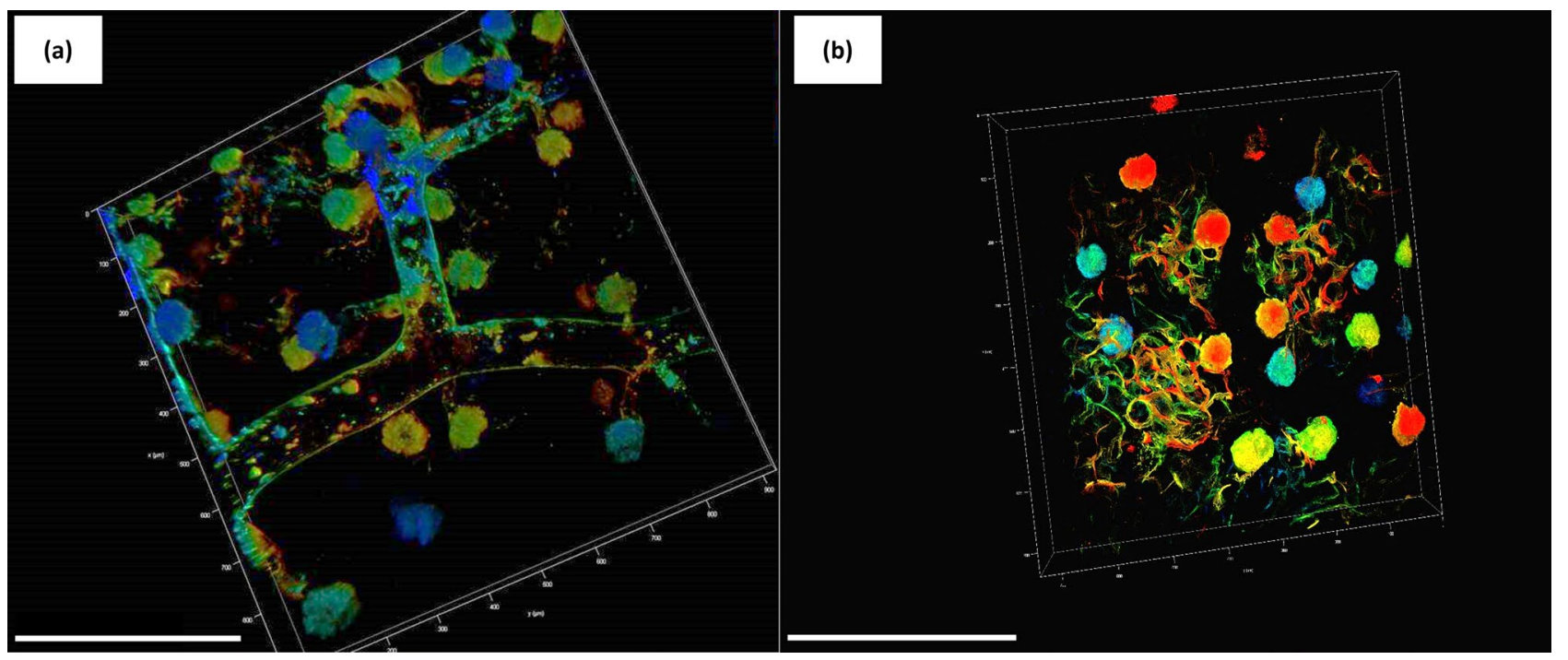

Fig. 2 3D images of a wild-type mouse kidney, strain C57/B16, perfused with the cationic dye MHI148-PEI (patented according to the code WO/2018/100089), cleared by the optimized ECi protocol (see Huang et al. 2019), and imaged by CM (Leica TCS SP8, Leica Biosystem, Wetzlar, Germany), with HC PL APO 20/0.7 IMM oil CORR CS2 objective. The renal artery (a) and glomeruli (b) are shown for a total depth of $110 \mu \mathrm{m}$. The depth coding on the upper right part of both images displays the depth reached during the imag-

with ECi clearing, which Klingberg and coworkers (2017) developed and Huang (2019) then optimized. The original protocol is based on a long incubation time $(\approx 16 \mathrm{~h})$ with an increasing ethanol gradient for delipidation and a further incubation with ECi for the sample clearing. The optimization allowed shortening the incubation time by automating the whole process and modifying the temperature (from $4{ }^{\circ} \mathrm{C}$ to room temperature) (Huang et al. 2019). Figure 2a, b shows an example of the optimized $\mathrm{ECi}$, where renal arteries, stained with MHI148-PEI (patented according to the code WO/2018/100089) and imaged by confocal microscopy, are depicted (Huang et al. 2019). For all the technical details, refer to Huang et al. (2019) and Brenna et al. (2020).

\section{Hydrogel-based OTCs in preclinical models}

The hydrogel-based methods (i.e., CLARITY, PACT) are suitable for clearing many organs in mouse models (Lee et al. 2014), albeit only a few robust data describe their use in clinical applications. The presence of a polymeric matrix protects biomolecules and retains endogenous fluorescence, and the transparency rate is near $100 \%$; the tissues present expansion after clearing. These protocols were also developed to overcome the fluorescence quenching issues and preserve the tissue structures better (Chung et al. 2013). Lipid extraction combining CLARITY with electrophoretic lipid ing. Specifically, the colored scale goes from the surface of the sample $(0-50 \mu \mathrm{m}$, in blue-light blue), middle part $(50-100 \mu \mathrm{m}$, in green $)$ up to the deepest part of the region $(100-150 \mu \mathrm{m}$, in yellow-red). Scale bars: $200 \mu \mathrm{m}$. The synthesis of the dye, mouse perfusion, sample harvesting, clearing, and imaging were conducted at the Zentrum für Medizinische Forschung (ZMF), Universitätsmedizin Mannheim (Germany)

extraction increases the rate. However, the heating (the electrophoretic CLARITY is performed at $42{ }^{\circ} \mathrm{C}$ ) might damage the sample. Therefore, PACT was designed to passively clear the a hydrogel-embedded sample with a faster SDS diffusion into the specimens (Treweek et al. 2015; Yang et al. 2014; Gradinaru et al. 2018). Data from both Yang et al. and Tomer and co-workers (2014) showed a moderate tissue expansion, which could be exploited to analyze smaller structural details with higher resolution. Both the retention of fluorescence and the clearing efficacy are very high (Tomer et al. 2014). In fact, the use of hydrogels does not protect only the biomolecules from degradation, but it also efficiently retains the endogenous fluorescence (Gradinaru et al. 2018). The major downsides lie in the long time required for the sample preparation, the use of toxic chemicals for both the hydrogel (e.g., acrylamide and bisacrylamide), and the reagent for the lipid removal (SDS, as mentioned before). Some alternatives have been proposed, such as, for instance, the FxClear protocol (Choi et al. 2019), a free hydrogel electrophoretic OTC method, for rapidly removing lipids and preserving the tissue immune reactivity. By removing the acrylamide, Choi and collaborators (2019) were able to increase both the imaging resolution and the retention of the fluorescence on the mouse brain. Moreover, when acrylamide-based techniques are used, the clearing of some samples is more difficult, especially in muscular tissue (Williams et al. 2019). To overcome these limitations, 
another method was recently described, Myoclear (Williams et al. 2019), based on hydrogel embedding. This procedure has been established for staining and clearing neuromuscular junctions and diaphragms from healthy and diseased mice, suitable for different staining procedures and the quantification of the neuromuscular junctions (Williams et al. 2019).

In preclinical glioblastoma models, CLARITY was tested to analyze brain vasculature and tumor microenvironment, allowing a more profound knowledge of glioblastoma networks (Lagerweij et al. 2017).

A refined CLARITY method was recently established and applied in mouse hearts, allowing the visualization of cardiac fibroblasts in vivo, both in uninjured and injured samples, for characterizing and better delineating the fibroblasts in the mouse heart (Fischesser et al. 2021). This advanced protocol overcame the limitations in existing tissue-clearing protocols that have attempted to identify specific cell types in the adult or neonatal heart (Nehrhoff et al. 2016; Kolesová et al. 2016; Yokoyama et al. 2017; Wang et al. 2018). PACT was used in the first studies for mouse heart clearing, but this method consented to reaching only $80 \mu \mathrm{m}$ of depth into the tissue (Yang et al. 2014; Tanaka et al. 2016; Fischesser et al. 2021).

Fixation for maintaining fibroblast fluorescence, a decolorization solution for reducing the autofluorescence created by the heme group within hemoglobin and myoglobin and enhancing the fluorescence from the reporter molecules, and equilibration of the tissue in refractive index matching solution (RIMS) are the steps optimized for CLARITY in this research (Fischesser et al. 2021). As a result, it could be possible to obtain images with a very high rate of tissue transparency, even in the ischemic areas, which are notoriously difficult to clear, reducing the autofluorescence produced by the fibroblast and the content of protein loss, and discriminating between healthy and injured cardiac tissues (Fischesser et al. 2021).

However, the long preparation times and toxicity of the chemicals used are still the main downsides. In addition, active CLARITY is characterized by the risk of epitope/ protein loss, resulting in an incorrect structure visualization (Kolesová et al. 2016; Lagerweij et al. 2017; Chen et al. 2019; Gómez-Gaviro et al. 2020).

\section{Clinical applications}

OTC-3D imaging might become an important tool for cancer diagnosis, as discussed previously. However, compared to animal models, such methodology might be more difficult. The two main pitfalls of this procedure are the impossibility of performing the perfusion in humans and the inaccessibility of organs. Secondly, many OTCs require immunostaining before the procedure, which is not always compatible with biopsies. Nevertheless, the new advances in tissue clearing, antibody penetration, and microscopy offer their potential to obtain detailed 3D images of cancer tissue. For example, cleared formalin-fixed paraffin-embedded biopsy samples from pancreatic, extrahepatic, and prostate tumors were successfully cleared, obtaining detailed 3D images from the cancerous areas (van Royen et al. 2016; Hong et al. 2020; Yoshizawa et al. 2020; Kolesová et al. 2021) and a visual description of a fatty invasion from a cleared human diabetic pancreas (Tang et al. 2018).

Different studies showed how solvent- and hydrogelbased protocols were used to give a more detailed comprehension of the histopathology in cancer of different human organs (Tanaka et al. 2017; Hong et al. 2020; Avilov 2021), and their potential suitability with a standard clinical workflow also been demonstrated, being compatible with formalin-fixed human specimens. In addition, ECi series is compatible with the fluorescence retainment and autofluorescence staining (Roshchina 2012; Hsueh et al. 2017; Chen et al. 2019; Brenna et al. 2020). Indeed, researchers have been reassessing the role of autofluorescence in recent times as a tool to track the inner structures, both as primary staining and in co-staining (Roshchina 2012; Brenna 2020). Autofluorescence is the primary and natural fluorescence provided by specific cellular components, such as hemoglobin, NADPH, aromatic amino acids, lipo-pigments, flavin, porphyrin, and some elements of the extracellular matrices (Rost 1992; Mori 2012; Roshchina 2012; Fred 2017). It has been demonstrated that it is possible to (i) acquire meaningful macro- and microanatomy images from different samples (e.g., mammalian glands, kidneys); (ii) discriminate between healthy and pathologic specimens by re-vitalizing old paraffin blocks, with following optical clearing and 3D imaging by confocal or multiphoton microscopy (Sabdyusheva Litschauer et al. 2020); and (iii) use the autofluorescence signal, provided by lipo-pigments or residual erythrocytes in the sample, to obtain accurate 3D spatial data and determine the shape and the position of individual cells, without the risky use of harmful chemicals for the operator and diminishing also the environmental and economic impacts (Mori et al. 2012; Layla et al. 2016). The risk in using autofluorescence is the depth reached that is lower than in other fluorescent markers. Despite OTC potentially also being clear in clinical routine, several key challenges still remain: the majority of these methods are not suitable for soft, fragile, and irregular tissue targets such as those commonly found in clinical settings, so a better optimization of these approaches is necessary; the use of specialized (and in some cases, corrosive) chemical tools represent obstacles for full adoption in clinical settings (Hsueh et al. 2017); the amount of data obtained after a 3D imaging, which ranges between gigabytes and terabytes, depends on the area analyzed, and this could be a problem both for clinicians and for patients. Moreover, all the necessary equipment to perform an OTC is 
highly expensive, and this could represent a strong limitation for those who cannot afford high costs for this diagnostic method.

\section{OTC alternatives: 3D imaging without optical clearing}

Different imaging technologies can be used to obtain a 3D image at a high level of resolution, up to nanometers, which do not require cleared specimens. They could be grouped into techniques that require or do not require the volumerendering application. Table 2 presents an overview of the most used clinical and medical imaging approaches that do not need optical clearing to obtain 3D images. The full name of the methodologies is listed in the section "Abbreviations."

The volume rendering-based techniques acquire images of $2 \mathrm{D}$ single slices that are then reconstructed into a $3 \mathrm{D}$ volume using specific imaging software programs. The images are usually acquired in a regular pattern (e.g., one slice every millimeter) with a standard number of image pixels. Examples of these techniques are computed tomography (CT) scan, magnetic resonance imaging (MRI), and X-ray microtomography (MicroCT).

Scanning transmission electron microscopy (STEM) does not include volume rendering image post-processing.

In STEM, the electron beam hits the sample in focus, and each pixel of the generated image contains information corresponding to the precise location of the sample with sub-ångström resolution (Crewe and Wall 1970). In medical sciences, STEM has been used to characterize the morphology of amyloid fibrils (Petkova et al. 2002; Diaz-Avalos et al. 2005).
During recent decades, STEM was combined with the serial block face approach (SBF-SEM) in different fields of life science research (Lippens et al. 2019). SBF-SEM is a relatively new technique, allowing the acquisition of serially sectioned, imaged, and digitally aligned ultrastructural data (Cocks et al. 2018). The main advantage of this technology lies in covering a range of volumes, from monolayers to multiple tissue layers, in all three dimensions. SBF-SEM was initially used in neuroscience and then expanded to other biological specimens, such as animal tissues, unicellular organisms, and plants (Borrett and Hughes 2016). Recently, SBF-SEM has been applied in murine models to explore the hepatic microarchitecture, allowing the assessment of largevolume morphometric data on parenchymal cells, sinusoids, and bile canaliculi, and it was also exploited to investigate the human placental microvasculature, revealing new intercellular connections (Shami 2016).

A wealth of information can be obtained from the resulting image stacks, albeit the computational analysis of the huge data sets produced still represents a new challenge for the researchers (Cocks et al. 2018). One approach is to reconstruct structures and features of interest in 3D. However, the software programs might be overwhelming, timeconsuming, and not intuitive for image analysis. Moreover, the alignment of the single slices could also be prone to error, and the sample preparation process for SBF-SEM is very long and consists of many elaborate steps (Lippens et al. 2019). Lastly, this 3D reconstruction covers only the outer face of the samples without investigating the inner structures and limiting the analysis only to the superficial features. Because of these limiting factors, only a limited number of published articles provide sufficient detail on this type of reconstruction (Cocks et al. 2018).

Table 2 Overview of methodologies involving 3D imaging without optical clearing and mostly used in the medical field

\begin{tabular}{|c|c|c|}
\hline Technique & Medical Imaging Sector & Reference(s) \\
\hline CT scan & $\begin{array}{l}\text { Pneumoencephalography; bronchography; upper gastrointes- } \\
\text { tinal and lower series; cholangiography; mammography; } \\
\text { angiography; venography }\end{array}$ & $\begin{array}{l}\text { Leeds and Kieffer et al. (2000); Ronald et al. (2005); Tonelli } \\
\text { et al. (2011); Bates et al. (2012); Mori et al. (2012); Unett } \\
\text { et al. (2013); Murphy et al. (2014); UK (2016) }\end{array}$ \\
\hline MRI & $\begin{array}{l}\text { Brain; neurography; cardiac (perfusion); angiography; chol- } \\
\text { angiopancreatography; }\end{array}$ & $\begin{array}{l}\text { Villringer (1988); Howe (1992); Prasad et al. (2001); Campeau } \\
\text { and Huston et al. (2012); von Knobelsdorff-Brenkenhoff } \\
\text { et al. (2017) }\end{array}$ \\
\hline Ultrasound & $\begin{array}{l}\text { Ecocardiography; gynecologic; obstetric; echoencephalogra- } \\
\text { phy; abdominal; ultrasonography carotid }\end{array}$ & $\begin{array}{l}\text { Caspi et al. (2003); Whitworth et al. (2015); Cleve et al. } \\
\text { (2018); Saxena et al. (2019) }\end{array}$ \\
\hline $\begin{array}{l}\text { Tomography } \\
\text { Array tomog- } \\
\text { raphy } \\
\text { CT } \\
\text { ECT } \\
\text { Magnetic induc- } \\
\text { tion tomog- } \\
\text { raphy } \\
\text { MicroCT }\end{array}$ & Brain connectome; myocardial imaging; cancer monitoring & $\begin{array}{l}\text { Koffie et al. (2009); Strauss and Bailey et al. (2009); Soiza- } \\
\text { Reilly and Commons et al. (2011); de Calignon et al. (2012); } \\
\text { Flottmann et al. (2012); Nanguneri et al. (2012); Kopeikina; } \\
\text { et al. (2013); Whitworth et al. (2015) }\end{array}$ \\
\hline
\end{tabular}


In its several variants, tomography is considered the progenitor of the volume rendering-based methodologies. MRI and CT are widely used in the medical field, especially for cancer monitoring, and they are both used to capture images within the human body. The main difference between them is that MRI uses radio waves and CT X-rays. For a detailed technical description of this imaging, refer to Kemmerer (1998) and Grover et al. (2015).

MRI was shown to be superior in regards to the image's detail. MRI can perform in vivo imaging in two ways: single-voxel spectroscopy and chemical shift imaging. Singlevoxel spectroscopy defines a voxel of interest within organs using gradients. The size of the voxel is predefined by the user and is the only source of the signal. Therefore, the number of signal averages acquired may be increased, requiring increased scanning time to improve the signal-to-noise ratio in smaller voxels. Chemical shift imaging (CSI) acquires spectra from a matrix of voxels, although it is usually done in one plane, instead of the three directions, hence the name 2D-single slice CSI. The advantage of single-voxel spectroscopy is in increasing the signal-to-noise ratio, whereas CSI allows wider anatomical coverage (Grover et al. 2015).

A CT scanner uses a motorized X-ray source, rotating around the circular opening of a donut-shaped structure called a gantry. During a CT scan, ionizing radiation (X-rays) coupled with an electronic detector records a density pattern and creates an image resulting from slices from the tissue (Caldemeyer and Buckwalter 1999). The $\mathrm{X}$-ay beam rotates around the object within the scanner. Multiple X-ay projections pass through the object, and the object's internal structure is reconstructed from the multiple projections of that object (Caldemeyer and Buckwalter 1999). The tissue thickness represented in each image slice usually ranges from 1 to $10 \mathrm{~mm}$ (Science Education 2013, https:/www.nibib.nih.gov/science-education/science-topics/ computed-tomography-ct). When a full slice is completed, the image is stored, and the X-ay scanning process is then repeated to produce another image slice (Science Education), repeating the process until the chosen number of slices is collected (Science Education). It is possible to acquire 3D images of the skeleton, organs, tissues, and any abnormalities. This method has many advantages, including rotating the $3 \mathrm{D}$ image in space or viewing slices in succession, making it easier to find the exact place where a problem may be located. Other differences between MRI and CT scans include their risks and benefits. CT scan risks consist of a very small dose of radiation and a potential side reaction to the use of the markers, whereas the main MRI risk is related to possible reactions to metals due to magnets (Science Education).

Both MRI and CT scans can view internal body structures. However, CT scanning is faster and provides images of tissues, organs, and skeletal structures. On the other hand,
MRI is highly adept at capturing images to determine abnormal tissues within the body. In addition, MRI provides more high-resolution images and, therefore, with more details.

The post-process imaging for both CT scanning and MRI involves using specific voxel-based morphometry algorithms (Dousset 1992; Rugg-Gunn et al. 2006; Flohr and Ohnesorge 2007). Post-processing methods represent an important improvement to conventional visual analysis but need to be interpreted with expertise to be apprehended as a complementary tool within the multimodal evaluation of the diseases (Martin 2015). Array tomography, developed by Micheva and Smith (2007), combines and extends the features of optical fluorescence and scanning electron microscopy, and it was initially designed to study synapses in the rodent brain (Micheva and Smith 2007). This method is based on embedding a tissue specimen in acrylic resin and cutting it into a series of very thin sections (50-200 nm) and gluing them to glass slides. The resulting array is labeled with fluorescent markers and imaged to generate ultra-highresolution volumetric images. The array can be repeatedly eluted, restained, and fluorescently imaged, and finally, it can also be stained with heavy metals and imaged with a scanning electron microscope (Micheva and Smith 2007). In mouse models, it has been used to characterize the synaptic protein composition in healthy brains (Micheva and Smith 2007; Soiza-Reilly and Commons 2011; Nanguneri 2012) and to demonstrate synaptic loss and proteins involved in synaptic degeneration in Alzheimer's disease models (Micheva and Smith 2007; Koffie 2009; de Calignon 2012; Kopeikina 2013).

Kai and coworkers (2013) used this methodology on postmortem human brains to investigate synapse degeneration in Alzheimer's disease, the contributions of specific apolipoproteins in Alzheimer's disease risk, and the mitochondrial size and distribution in neurons of a tauopathy mouse model and human Alzheimer patients. In addition, array tomography is suitable for examining many other small biological structures' morphology, localization, and protein composition. For example, it was exploited to investigate the microstructural changes in blood vessel walls during abdominal aortic aneurysms in mice (Saatchi 2012), or the collagenous matrix of the human optic nerve head (Winkler 2010). Furthermore, this approach guarantees images with a better spatial resolution than confocal microscopy, although it is limited only to fixed specimens; it is also not suitable for in vivo imaging (Micheva and Smith 2007), and all the procedure is cumbersome and highly time-consuming.

In general, besides the great advantages and benefits of these technologies in the medical and diagnosis fields, there are still some downsides. First, these procedures might give inexact results. They represent a compromise between the accuracy and computation time required, leading to producing artifacts (errors in the reconstruction) at a 
higher computing cost (Herman 2009). Moreover, all these approaches do not image the inner structures but only the surface of the samples. In modern society, where several diseases have been rising, it would be relevant to know and better decipher the structural changes within the organ in order to define the primary cause of the disease and not only the consequences, as, for instance, the abnormal tissue, which is generated from previous steps.

\section{Conclusions and future perspectives}

The increasing need to discover anatomic details leads researchers to develop and design more accurate technologies to be included in clinical applications. 3D imaging is deeply rooted in routine and cancer fields, although only superficial anatomic features can be imaged so far.

Over the recent decades, the roles of OTC and 3D fluorescent imaging in the clinical field have been gaining importance, given the possibility to follow the development of the pathology and establish new medical treatments. Furthermore, with the advent of organoids and spheroids, it is possible to think about a new and modern 3D biology, both in vitro and in vivo, with preclinical and clinical studies.

The high-resolution 3D imaging of protein structures within cleared tumors appears necessary to understand the development of a disease, especially in oncology, considering the high variability of the tumor environment.

With this review, we wanted to assess the state of the art of 3D imaging in clinical applications. OTC-3D imaging is still far from being included in routine and cancer diagnosis and monitoring, but this approach might facilitate and increase new knowledge in tumor biology by facilitating the discovery of new pharmaceutical targets and quantifying the drug penetration. Moreover, the 3D study of the penetration and distribution rate and its interaction in the target region may provide advanced information about treatment responses. Therefore, it is necessary to better understand the drug behavior in the whole human body to further develop personalized medicine. Moreover, researchers should be encouraged to design more accurate OTCs, which could be used in patients, to establish a more tailored medicine.

Acknowledgements The authors are grateful to ZMF (Mannheim, DE) for permitting them to publish original images of 3D renal arteries and glomeruli acquired by C.B. during her Ph.D.

Author contributions $\mathrm{CB}, \mathrm{LMN}$ : idealization, intellectual input. $\mathrm{CB}$, $\mathrm{CS}$, and IC: literature search and writing the initial version of the manuscript. MM: literature search and drafting the new part of the text. GV and EC: manuscript editing. LMN: manuscript editing and supervision. All authors have read and agreed to the submitted version of the manuscript.
Funding Open access funding provided by Università degli Studi di Ferrara within the CRUI-CARE Agreement. This study was supported by "Local Research grants" from the University of Ferrara, Italy: Fondo per l'Incentivazione alla Ricerca (FIR), P.I. L.M.N; Fondo di Ateneo per la Ricerca Scientifica (FAR), P:I L.M.N; FAR, P.I. C.S. European Funding: POR-FESR 201-2020 BIOPHOTOMICS UNIFE-CUP F71F18000140009, P.I. L.M.N.

Availability of data and material Not applicable.

Code availability Not applicable.

\section{Declarations}

Conflict of interest The authors declare no conflict of interest.

Ethical approval Not applicable.

Consent to participate Not applicable.

Consent for publication Not applicable.

Open Access This article is licensed under a Creative Commons Attribution 4.0 International License, which permits use, sharing, adaptation, distribution and reproduction in any medium or format, as long as you give appropriate credit to the original author(s) and the source, provide a link to the Creative Commons licence, and indicate if changes were made. The images or other third party material in this article are included in the article's Creative Commons licence, unless indicated otherwise in a credit line to the material. If material is not included in the article's Creative Commons licence and your intended use is not permitted by statutory regulation or exceeds the permitted use, you will need to obtain permission directly from the copyright holder. To view a copy of this licence, visit http://creativecommons.org/licenses/by/4.0/.

\section{References}

Alépée N, Bahinski A, Daneshian M, De Wever B et al (2014) Stateof-the-art of 3D cultures (organs-on-a-chip) in safety testing and pathophysiology. Altex 31(4):441-477

Almagro J, Messal HA, Zaw TM, van Rheenen J, Behrens A (2021) Tissue clearing to examine tumour complexity in three dimensions. Nat Rev Cancer 21(11):718-730

Antonacci G, Braakman S (2016) Biomechanics of subcellular structures by non-invasive Brillouin microscopy. Sci Rep 6(1):37217

Ariel P (2017) A beginner's guide to tissue clearing. Int J Biochem 84:35-39

Au Haass-Koffler CL, Au-Naeemuddin M, Au Bartlett SE (2012) An Analytical Tool that Quantifies Cellular Morphology Changes from Three-dimensional Fluorescence Images. JoVE 66:e4233

Avilov SV (2021) Navigating across multi-dimensional space of tissue clearing parameters. Methods Appl Fluoresc 9(2):022001

Barcellos-Hoff MH, Aggeler J, Ram TG, Bissell MJ (1989) Functional differentiation and alveolar morphogenesis of primary mammary cultures on reconstituted basement membrane. Development 105(2):223-235

Bates SM, Jaeschke R, Stevens SM, Goodacre S et al (2012) Diagnosis of DVT: antithrombotic therapy and prevention of thrombosis, 9th ed: American college of chest physicians evidence-based clinical practice guidelines. Chest 141(2 Suppl):351-418 
Borrett S, Hughes L (2016) Reporting methods for processing and analysis of data from serial block face scanning electron microscopy. J Microsc 263(1):3-9

Brenna C, Khan AUM, Picascia T, Sun Q, Heuveline V, Gretz N (2020) New technical approaches for 3D morphological imaging and quantification of measurements. Anat Rec 303(10):2702-2715

Cai R, Pan C, Ghasemigharagoz A, Todorov MI et al (2019) Panoptic imaging of transparent mice reveals whole-body neuronal projections and skull-meninges connections. Nat Neurosci 22(2):317-327

Caldemeyer KS, Buckwalter KA (1999) The basic principles of computed tomography and magnetic resonance imaging. J Am Acad Dermatol 41(5 Pt 1):768-771

Campeau NG, Huston J 3rd (2012) Vascular disorders-magnetic resonance angiography: brain vessels. Neuroimaging Clin N Am 22(2):207-233

Carrillo M, Chuecos M, Gandhi K, Bednov A et al (2018) Optical tissue clearing in combination with perfusion and immunofluorescence for placental vascular imaging. Medicine (Baltimore) 97(39):e12392

Caspi B, Zbar AP, Mavor E, Hagay Z, Appelman Z (2003) The contribution of transvaginal ultrasound in the diagnosis of acute appendicitis: an observational study. Ultrasound Obstet Gynecol 21(3):273-276

Chen Y, Shen Q, White SL, Gokmen-Polar Y, Badve S, Goodman LJ (2019) Three-dimensional imaging and quantitative analysis in CLARITY processed breast cancer tissues. Sci Rep 9(1):5624

Christopher GR, Oliver FS, Thomas EM, Nathaniel K et al (2006) Dehydration mechanism of optical clearing in tissue. J Biomed Opt 11(4):1-7

Choi J, Lee E, Kim JH, Sun W (2019) FxClear, a free-hydrogel electrophoretic tissue clearing method for rapid de-lipidation of tissues with high preservation of immunoreactivity. Exp Neurobiol 28:436

Chung K, Wallace J, Kim S-Y, Kalyanasundaram S et al (2013) Structural and molecular interrogation of intact biological systems. Nature 497(7449):332-337

Cleve J, McCulloch Marti L (2018) onducting a Cardiac Ultrasound Examination, Echocardiography. Springer International Publishing, pp 33-42

Cocks E, Taggart M, Rind FC, White K (2018) A guide to analysis and reconstruction of serial block face scanning electron microscopy data. J Microsc 270(2):217-234

Colella G, Fazioli F, Gallo M, De Chiara A et al (2018) Sarcoma spheroids and organoids-promising tools in the era of personalized medicine. Int J Mol Sci 19(2):615

Cora V, Haderspeck J, Antkowiak L, Mattheus U et al (2019) A cleared view on retinal organoids. Cells 8(5):391

Costa EC, Silva DN, Moreira AF, Correia IJ (2019) Optical clearing methods: an overview of the techniques used for the imaging of 3D spheroids. Biotechnol Bioeng 116(10):2742-2763

Crewe AV, Wall J (1970) A scanning microscope with 5 A resolution. J Mol Biol 48(3):375-393

Cuccarese MF, Dubach JM, Pfirschke C, Engblom C et al (2017) Heterogeneity of macrophage infiltration and therapeutic response in lung carcinoma revealed by $3 \mathrm{D}$ organ imaging. Nat Commun $8(1): 14293$

Davis FM, Lloyd-Lewis B, Harris OB, Kozar S et al (2016) Singlecell lineage tracing in the mammary gland reveals stochastic clonal dispersion of stem/progenitor cell progeny. Nat Commun 7(1):13053

Dawson CA, Pal B, Vaillant F, Gandolfo LC et al (2020) Tissueresident ductal macrophages survey the mammary epithelium and facilitate tissue remodelling. Nat Cell Biol 22:546-558
Dawson CA, Mueller SN, Lindeman GJ, Rios AC, Visvader JE (2021) Intravital microscopy of dynamic single-cell behavior in mouse mammary tissue. Nat Protoc 16(4):1907-1935

de Calignon A, Polydoro M, Suárez-Calvet MC, William DH et al (2012) Propagation of tau pathology in a model of early Alzheimer's disease. Neuron 73(4):685-697

Dekkers JF, Alieva M, Wellens LM, Ariese HCR et al (2019) Highresolution 3D imaging of fixed and cleared organoids. Nat Protoc 14(6):1756-1771

Denk W, Strickler JH, Webb WW (1990) Two-photon laser scanning fluorescence microscopy. Science 248(4951):73-76

Diaz-Avalos R, King CY, Wall J, Simon M, Caspar DLD (2005) Strain-specific morphologies of yeast prion amyloid fibrils. PNAS 102(29):10165

Dobosz M, Ntziachristos V, Scheuer W, Strobel S (2014) Multispectral fluorescence ultramicroscopy: three-dimensional visualization and automatic quantification of tumor morphology, drug penetration, and antiangiogenic treatment response. Neoplasia 16(1):1-13

Dousset V, Grossman RI, Ramer KN, Schnall MD et al (1992) Experimental allergic encephalomyelitis and multiple sclerosis: lesion characterization with magnetization transfer imaging. Radiology 182(2):483-491

Duval K, Grover H, Han LH, Mou Y et al (2017) Modeling physiological events in 2D vs 3D cell culture. Physiology (Bethesda) 32(4):266-277

Eiraku M, Watanabe K, Matsuo-Takasaki M, Kawada M et al (2008) Self-organized formation of polarized cortical tissues from ESCs and its active manipulation by extrinsic signals. Cell Stem Cell 3(5):519-532

Ertürk A, Becker K, Jährling N, Mauch CP (2012) Three-dimensional imaging of solvent-cleared organs using 3DISCO. Nat Protoc 7:1983-1995

Feuchtinger A, Walch A, Dobosz M (2016) Deep tissue imaging: a review from a preclinical cancer research perspective. Histochem Cell Biol 146(6):781-806

Fischesser DM, Meyer EC, Sargent M, Molkentin JD (2021) Refined CLARITY-based tissue clearing for three-dimensional fibroblast organization in healthy and injured mouse hearts. J Vis Exp. https://doi.org/10.3791/62023

Flohr, T. and B. Ohnesorge (2007). Image Visualization and Postprocessing Techniques. Multi-slice and Dual-source CT in Cardiac Imaging: Principles - Protocols - Indications - Outlook.

Fred R (2017) Fluorescence microscopy, applications. Ashfield, Elsevier Ltd

Genina EA, Bashkatov AN, Tuchin VV (2010) Tissue optical immersion clearing. Expert Rev Med Devices 7(6):825-842

Glaser AK, Reder NP, Chen Y, McCarty EF et al (2017) Light-sheet microscopy for slide-free non-destructive pathology of large clinical specimens. Nat Biomed 1(7):0084

Gómez-Gaviro MV, Sanderson D, Ripoll J, Desco M (2020) Biomedical applications of tissue clearing and three-dimensional imaging in health and disease. iScience 23(8):101432

Gradinaru V, Treweek J, Overton K, Deisseroth K (2018) Hydrogeltissue chemistry: principles and applications. Annu Rev Biophys 47:355-376

Grover VP, Tognarelli JM, Crossey MM, Cox IJ et al (2015) Magnetic resonance imaging: principles and techniques: lessons for clinicians. J Clin Exp Hepatol 5(3):246-255

Guldner IH, Yang L, Cowdrick KR, Wang Q et al (2016) An integrative platform for three-dimensional quantitative analysis of spatially heterogeneous metastasis landscapes. Sci Rep 6(1):24201

Ham SL, Joshi R, Luker GD, Tavana H (2016) Engineered breast cancer cell spheroids reproduce biologic properties of solid tumors. Adv Healthc Mater 5(21):2788-2798 
Ham SL, Thakuri PS, Plaster M, Li J, Luker KE, Luker GD, Tavana H (2017) Three-dimensional tumor model mimics stromal-breast cancer cells signaling. Oncotarget 9(1):249

Hasegawa S, Susaki EA, Tanaka T, Komaba H et al (2019) Comprehensive three-dimensional analysis (CUBIC-kidney) visualizes abnormal renal sympathetic nerves after ischemia/reperfusion injury. Kidney Int 96(1):129-138

Herman GT (2009) Fundamentals of Computerized Tomography in Image in Reconstruction from Projections, 2nd edn. Springer

Hong SM, Jung D, Kiemen A, Gaida MM et al (2020) Three-dimensional visualization of cleared human pancreas cancer reveals that sustained epithelial-to-mesenchymal transition is not required for venous invasion. Mod Pathol 33(4):639-647

Hong SM, Noë M, Hruban CA, Thompson ED, Wood LD, Hruban RH (2019) A "Clearer" view of pancreatic pathology: a review of tissue clearing and advanced microscopy techniques. Adv Anat Pathol 26(1):31-39

Howe FA, Filler AG, Bell BA, Griffiths JR (1992) Magnetic resonance neurography. Magn Reson Med 28(2):328-338

Hsueh B, Burns VM, Pauerstein P, Holzem K et al (2017) Pathways to clinical CLARITY: volumetric analysis of irregular, soft, and heterogeneous tissues in development and disease. Sci Rep 7(1):5899

Huang J, Brenna C, Khan AUM, Daniele C, Rudolf R, Heuveline V, Gretz N (2019) A cationic near infrared fluorescent agent and ethyl-cinnamate tissue clearing protocol for vascular staining and imaging. Sci Rep 9(1):521

Jamieson PR, Dekkers JF, Rios AC, Fu NY et al (2017) Derivation of a robust mouse mammary organoid system for studying tissue dynamics. Development 144(6):1065-1071

Jing D, Yi Y, Luo W, Zhang S et al (2019) Tissue clearing and its application to bone and dental tissues. J Dent Res 98(6):621-631

Kay KR, Smith C, Wright AK, Serrano-Pozo A et al (2013) Studying synapses in human brain with array tomography and electron microscopy. Nat Protoc 8(7):1366-1380

Keller PJ, Dodt HU (2012) Light sheet microscopy of living or cleared specimens. Curr Opin Neurobiol 22(1):138-143

Kemmerer SR, Mortele KJ, Ros PR (1998) CT SCAN OF THE LIVER. Radiol Clin North Am 36(2):247-261

Khawar IA, Park JK, Jung ES, Lee MA, Chang S, Kuh HJ (2018) Three dimensional mixed-cell spheroids mimic stroma-mediated chemoresistance and invasive migration in hepatocellular carcinoma. Neoplasia 20(8):800-812

Kim J, Koo BK, Knoblich JA (2020) Human organoids: model systems for human biology and medicine. Nat Rev Mol Cell Biol 21(10):571-584

Klingberg A, Hasenberg A, Ludwig-Portugall I, Medyukhina A et al (2017) Fully automated evaluation of total glomerular number and capillary tuft size in nephritic kidneys using lightsheet microscopy. J Am Soc Nephrol 28(2):452-459

Koffie RM, Meyer-Luehmann M, Hashimoto T, Adams KW et al (2009) Oligomeric amyloid $\beta$ associates with postsynaptic densities and correlates with excitatory synapse loss near senile plaques. Proc Nat Acad Sci. https://doi.org/10.1073/pnas.08116

Kolesová H, Čapek M, Radochová B, Janáček J, Sedmera D (2016) Comparison of different tissue clearing methods and 3D imaging techniques for visualization of GFP-expressing mouse embryos and embryonic hearts. Histochem Cell Biol 146(2):141-152

Kolesová H, Olejníčková V, Kvasilová A, Gregorovičová M, Sedmera D (2021) Tissue clearing and imaging methods for cardiovascular development. iScience 24(4):102387

Kopeikina KJ, Polydoro M, Tai HC, Yaeger E et al (2013) Synaptic alterations in the rTg4510 mouse model of tauopathy. J Comp Neurol 521(6):1334-1353
Krieger TG, Tirier SM, Park J, Jechow K et al (2020) Modeling glioblastoma invasion using human brain organoids and single-cell transcriptomics. Neuro Oncol 22(8):1138-1149

Křížek P, Lukeš T, Ovesný M, Fliegel K, Hagen GM (2016) SIMToolbox: a MATLAB toolbox for structured illumination fluorescence microscopy. Bioinformatics 32(2):318-320

Kubota SI, Takahashi K, Nishida J, Morishita Y et al (2017) Wholebody profiling of cancer metastasis with single-cell resolution. Cell Rep 20(1):236-250

Lagerweij T, Dusoswa SA, Negrean A, Hendrikx EML et al (2017) Optical clearing and fluorescence deep-tissue imaging for 3D quantitative analysis of the brain tumor microenvironment. Angiogenesis 20(4):533-546

Lancaster MA, Renner M, Martin CA, Wenzel D et al (2013) Cerebral organoids model human brain development and microcephaly. Nature 501(7467):373-379

Lang SH, Stark M, Collins A, Paul AB, Stower MJ, Maitland NJ (2001) Experimental prostate epithelial morphogenesis in response to stroma and three-dimensional matrigel culture. Cell Growth Differ 12(12):631-640

Lang S (2019) What are the pros and cons of using organoids? https:// www.drugtargetreview.com/article/48244/what-are-the-prosand-cons-of-using-organoids/

Layla P, Valentin D, Vitkin IA, Vanderlei SB, Kurachi C, Brian CW (2016) Optical clearing of melanoma in vivo: characterization by diffuse reflectance spectroscopy and optical coherence tomography. J Biomed Opt 21(8):1-9

Lazzari G, Nicolas V, Matsusaki M, Akashi M, Couvreur P, Mura S (2018) Multicellular spheroid based on a triple co-culture: A novel 3D model to mimic pancreatic tumor complexity. Acta Biomater 78:296-307

Lee H, Park JH, Seo I, Park SH, Kim S (2014) Improved application of the electrophoretic tissue clearing technology, CLARITY, to intact solid organs including brain, pancreas, liver, kidney, lung, and intestine. BMC Dev Bio 14(1):48

Leeds NE, Kieffer SA (2000) Evolution of diagnostic neuroradiology from 1904 to 1999. Radiology 217(2):309-318

Linde N, Casanova-Acebes M, Sosa MS, Mortha A et al (2018) Macrophages orchestrate breast cancer early dissemination and metastasis. Nat Commun. https://doi.org/10.1038/s41467-017-02481-5

Lippens S, Kremer A, Borghgraef P, Guérin CJ (2019) Chapter 4Serial block face-scanning electron microscopy for volume electron microscopy. Methods Cell Biol. 152:69-85

Lloyd-Lewis B, Davis FM, Harris OB, Hitchcock JR et al (2016) Imaging the mammary gland and mammary tumours in $3 \mathrm{D}$ : optical tissue clearing and immunofluorescence methods. Breast Cancer Res 18(1):127

Martin P, Bender B, Focke NK (2015) Post-processing of structural MRI for individualized diagnostics. Quant Imaging Med Surg 5(2):188-203

Martinelli LP, Iermak I, Moriyama LT, Requena MB, Pires L, Kurachi C (2020) Optical clearing agent increases effectiveness of photodynamic therapy in a mouse model of cutaneous melanoma: an analysis by Raman microspectroscopy. Biomed Opt Express 11(11):6516-6527

Matryba P, Kaczmarek L, Gołąb J (2019) Advances in ex situ tissue optical clearing. Laser Photonics Rev 13(8):1800292

Micheva KD, Smith SJ (2007) Array tomography: a new tool for imaging the molecular architecture and ultrastructure of neural circuits. Neuron 55(1):25-36

Minsky M (1988) Memoir on inventing the confocal scanning microscope. Scanning 10(4):128-138

Mori H, Borowsky AD, Bhat R, Ghajar CM, Seiki M, Bissell MJ (2012) Laser scanning-based tissue auto-fluorescence/fluorescence imaging (LS-TAFI), a new technique for analysis of microanatomy in whole-mount tissues. Am J Path 180(6):2249-2256 
Murphy KP, McLaughlin PD, O’Connor OJ, Maher MM (2014) Imaging the small bowel. Curr Opin Gastroenterol 30(2):134-140

Nanguneri S, Flottmann B, Horstmann H, Heilemann M, Kuner T (2012) Three-dimensional, tomographic super-resolution fluorescence imaging of serially sectioned thick samples. PLoS One 7(5): 38098

Nehrhoff I, Bocancea D, Vaquero J, Vaquero JJ et al (2016) 3D imaging in CUBIC-cleared mouse heart tissue: going deeper. Biomed Opt Express 7(9):3716-3720

Nojima S, Susaki EA, Yoshida K, Takemoto H et al (2017) CUBIC pathology: three-dimensional imaging for pathological diagnosis. Sci Rep 7(1):9269

Nürnberg E, Vitacolonna M, Klicks J, von Molitor E et al (2020) Routine optical clearing of 3D-cell cultures: simplicity forward. Front Mol Biosci. https://doi.org/10.3389/fmolb.2020.00020

Ochoa LF, Kholodnykh A, Villarreal P, Tian B et al (2018) Imaging of murine whole lung fibrosis by large scale 3D microscopy aided by tissue optical clearing. Sci Rep 8(1):13348

Palaiologou E, Goggin P, Chatelet DS, Ribeiro de Souza R et al (2020) Serial block-face scanning electron microscopy reveals novel intercellular connections in human term placental microvasculature. J Anat 237(2):241-249

Paravastu AK, Leapman RD, Yau W-M, Tycko R (2008) Molecular structural basis for polymorphism in Alzheimer's $\beta$-amyloid fibrils. PNAS 105(47):18349-18354

Pauli C, Hopkins BD, Prandi D, Shaw R et al (2017) Personalized in vitro and in vivo cancer models to guide precision medicine. Cancer Discov 7(5):462-477

Perkhofer L, Frappart PO, Müller M, Kleger A (2018) Importance of organoids for personalized medicine. J Pers Med 15(6):461-465

Petkova AT, Ishii Y, Balbach JJ, Antzutkin ON et al (2002) A structural model for Alzheimer's $\beta$-amyloid fibrils based on experimental constraints from solid state NMR. PNAS 99(26):16742-16747

Poola PK, Afzal M, Yoo Y, Kim KH, Chung E (2019) Light sheet microscopy for histopathology applications. Biomed Eng Lett. https://doi.org/10.1007/s13534-019-00122-y

Prasad SR, Sahani D, Saini S (2001) Clinical applications of magnetic resonance cholangiopancreatography. J Clin Gastroenterol 33(5):362-366

Richardson DS, Lichtman JW (2015) Clarifying tissue clearing. Cell 162(2):246-257

Rios AC, Capaldo BD, Vaillant F, Pal B, van Ineveld R, Dawson CA et al (2019) Intraclonal plasticity in mammary tumors revealed through large-scale single-cell resolution 3D imaging. Cancer Cell 35:618-632.e6

Ronald BG (2005) Chest medicine: essentials of pulmonary and critical care medicine, 5th edn. Lippincott Williams \& Wilkins, p 83

Roshchina V (2012) Vital auto-fluorescence: Application to the study of plant living cells. Int J Spectrosc 2012:1-14

Rost FW (1992) Fluorescence microscopy. Cambridge University Press

Rugg-Gunn FJ, Boulby PA, Symms MR, Barker GJ, Duncan JS (2006) Imaging the neocortex in epilepsy with double inversion recovery imaging. Neuroimage 31(1):39-50

Saatchi S, Azuma J, Wanchoo N, Smith SJ et al (2012) Three-dimensional microstructural changes in murine abdominal aortic aneurysms quantified using immunofluorescent array tomography. $\mathrm{J}$ Histochem Cytochem 60(2):97-109

Sabdyusheva Litschauer I, Becker K, Saghafi S et al (2020) 3D histopathology of human tumours by fast clearing and ultramicroscopy. Sci Rep 10(1):17619

Salomon LJ, Alfirevic Z, Berghella V, Bilardo C et al (2011) Practice guidelines for performance of the routine mid-trimester fetal ultrasound scan. Ultrasound Obstet Gynecol 37(1):116-126

Saxena A, Ng EYK, Lim ST (2019) Imaging modalities to diagnose carotid artery stenosis: progress and prospect. BioMed EngOnLine 18(1):66
Schindelin J, Arganda-Carreras I, Frise E, Kaynig V (2012) Fiji: an open-source platform for biological-image analysis. Nat Meth 9(7):676-682

Science Education, b. N. I. o. B. I. a. B. Computed Tomography (CT) (2013) https://www.nibib.nih.gov/science-education/science-topics/computed-tomography-ct

Scott GD, Blum ED, Fryer AD, Jacoby DB (2014) Tissue optical clearing, three-dimensional imaging, and computer morphometry in whole mouse lungs and human airways. Am J Respir Cell Mol Biol 51(1):43-55

Seo J, Choe M, Kim SY (2016) Clearing and labeling techniques for large-scale biological tissues. Mol Cells 39(6):439-446

Shami GJ, Cheng D, Huynh M, Vreuls C, Wisse E, Braet F (2016) 3-D EM exploration of the hepatic microarchitecture-lessons learned from large-volume in situ serial sectioning. Sci Rep 6(1):36744

Silvestri L, Costantini I, Sacconi L, Pavone FS (2016) Clearing of fixed tissue: a review from a microscopist's perspective. J Biomed Opt 21(8):081205

Soiza-Reilly M, Commons KG (2011) Quantitative analysis of glutamatergic innervation of the mouse dorsal raphe nucleus using array tomography. J Comp Neurol 519(18):3802-3814

Strauss HW, Bailey D (2009) Resurrection of thallium-201 for myocardial perfusion imaging. JACC Cardiovasc Imaging United States 2:283-285

Sun Q, Picascia T, Khan AUM, Brenna C et al (2020) Application of ethyl cinnamate based optical tissue clearing and expansion microscopy combined with retrograde perfusion for 3D lung imaging. Exp Lung Res 46(10):393-408

Susaki E, Tainaka A, Perrin K, Kishino D et al (2014) Whole-brain imaging with single-cell resolution using chemical cocktails and computational analysis. Cell 157(3):726-739

Tainaka K, Kubota SI, Suyama TQ, Susaki EA et al (2014) Wholebody imaging with single-cell resolution by tissue decolorization. Cell 159(4):911-924

Tainaka K, Murakami TC, Susaki EA, Shimizu C et al (2018) Chemical landscape for tissue clearing based on hydrophilic reagents. Cell Rep 24(8):2196-2210.e2199

Takahashi K, Kubota SI, Ehata S, Ueda HR, Miyazono K (2020) Protocol for imaging and analysis of mouse tumor models with CUBIC tissue clearing. STAR Protocols 1(3):100191

Tanaka N, Kanatani S, Tomer R, Sahlgren C et al (2017) Whole-tissue biopsy phenotyping of three-dimensional tumours reveals patterns of cancer heterogeneity. Nat Biomed Eng 1(10):796-806

Tang SC, Baeyens L, Shen CN, Peng S et al (2018) Human pancreatic neuro-insular network in health and fatty infiltration. Diabetologia 61(1):168-181

Tomer R, Ye L, Hsueh B, Deisseroth, (2014) Advanced CLARITY for rapid and high-resolution imaging of intact tissues. Nat Protoc 9(7):1682-1697

Tonelli M, Connor Gorber S, Joffres M, Dickinson J et al (2011) Recommendations on screening for breast cancer in average-risk women aged 40-74 years. CMAJ 183(17):1991-2001

Treweek JB, Chan KY, Flytzanis NC, Yang B et al (2015) Whole-body tissue stabilization and selective extractions via tissue-hydrogel hybrids for high-resolution intact circuit mapping and phenotyping. Nat Protoc 10(11):1860-1896

van Ineveld RL, Ariese HCR, Wehrens EJ, Dekkers JF, Rios AC (2020) Single-cell resolution three-dimensional imaging of intact organoids. J Vis Exp. https://doi.org/10.3791/60709

van Royen ME, Verhoef EI, Kweldam CF, van Cappellen WA et al (2016) Three-dimensional microscopic analysis of clinical prostate specimens. Histopathology 69(6):985-992

Verhoef EI, van Cappellen WA, Slotman JA, Kremers GJ et al (2019) Three-dimensional analysis reveals two major architectural 
subgroups of prostate cancer growth patterns. Mod Path 32(7):1032-1041

Unett EM, Campling J, Royle AJ (2013) Radiographic Techniques and Image Evaluation. Springer-Science +Business Media, BV, pp 306-307

Villringer A, Rosen BR, Belliveau JW, Ackerman JL et al (1988) Dynamic imaging with lanthanide chelates in normal brain: contrast due to magnetic susceptibility effects. Magn Reson Med 6(2):164-174

von Knobelsdorff-Brenkenhoff F, Pilz G, Schulz-Menger J (2017) Representation of cardiovascular magnetic resonance in the AHA/ ACC guidelines. J Cardiovasc Magn Reson 19(1):70

von Neubeck B, Gondi G, Riganti C, Pan C (2018) An inhibitory antibody targeting carbonic anhydrase XII abrogates chemoresistance and significantly reduces lung metastases in an orthotopic breast cancer model in vivo. Int J Cancer 143(8):2065-2075

Wang Z, Zhang J, Fan G, Zhao H et al (2018) Imaging transparent intact cardiac tissue with single-cell resolution. Biomed Opt Express 9(2):423-436

Whitworth M, Bricker L, Mullan C (2015) Ultrasound for fetal assessment in early pregnancy. Cochrane Database Syst Rev 2015(7):Cd007058

Williams MPI, Rigon M, Straka T, Hörner SJ et al (2019) A novel optical tissue clearing protocol for mouse skeletal muscle to visualize endplates in their tissue context. Front Cell Neurosci. https://doi. org/10.3389/fncel.2019.00049
Winkler M, Jester B, Nien-Shy C, Massei S et al (2010) High resolution three-dimensional reconstruction of the collagenous matrix of the human optic nerve head. Brain Res Bull 81(2-3):339-348

Yang B, Treweek JB, Kulkarni RP, Deverman BE et al (2014) Singlecell phenotyping within transparent intact tissue through wholebody clearing. Cell 158(4):945-958

Yokoyama T, Lee JK, Miwa K, Opthof T et al (2017) Quantification of sympathetic hyperinnervation and denervation after myocardial infarction by three-dimensional assessment of the cardiac sympathetic network in cleared transparent murine hearts. PLoS One. https://doi.org/10.1371/journal.pone.0182072

Yoshizawa T, Hong SM, Jung D, Noë M et al (2020) Three-dimensional analysis of extrahepatic cholangiocarcinoma and tumor budding. J Path 251(4):e5474

Zschenker O, Streichert T, Hehlgans S, Cordes N (2012) Genome-wide gene expression analysis in cancer cells reveals $3 \mathrm{~d}$ growth to affect ECM and processes associated with cell adhesion but not DNA repair. PLOS One 7(4):e34279

Publisher's Note Springer Nature remains neutral with regard to jurisdictional claims in published maps and institutional affiliations.

\section{Authors and Affiliations}

\section{Cinzia Brenna ${ }^{1,2} \cdot$ Carolina Simioni $^{3,4} \cdot$ Gabriele Varano $^{1} \cdot$ Ilaria Conti ${ }^{1} \cdot$ Eva Costanzi $^{1} \cdot$ Mattia Melloni $^{1}$. Luca Maria Neri ${ }^{1,4}$ (1)}

\author{
Cinzia Brenna \\ cinzia.brenna@unife.it \\ Carolina Simioni \\ carolina.simioni@unife.it \\ Gabriele Varano \\ gabriele.varano@unife.it \\ Ilaria Conti \\ ilaria.conti@unife.it \\ Eva Costanzi \\ eva.costanzi@unife.it \\ Mattia Melloni \\ mattia.melloni@unife.it
}

1 Department of Translational Medicine, University of Ferrara, 44121 Ferrara, Italy

2 Medical Research Center, Medical Faculty Mannheim, University of Heidelberg, Theodor-Kutzer-Ufer 1-3, 68167 Mannheim, Germany

3 Department of Life Sciences and Biotechnology, University of Ferrara, 44121 Ferrara, Italy

4 LTTA - Electron Microscopy Center, University of Ferrara, 44121 Ferrara, Italy 